\title{
The Profile and Work of Officials in Central and Regional Administration Compared: The Case of the Czech Republic ${ }^{1}$
}

Arnošt Veselý2

\begin{abstract}
This paper examines the profiles and work tasks of officials in central and regional administration in the Czech Republic. It analyzes data from surveys among the officials of eleven ministries in $2013(\mathrm{~N}=1351)$ and fourteen regional offices in 2012 $(\mathrm{N}=783)$. First, the profile of ministerial officials (MOs) is compared with that of regional-level officials (ROs). In accordance with our hypotheses, on average it is found that MOs are, when compared to ROs, older, more educated and have spent more time in civil service. There is also a higher proportion of men in ministries than in regional offices. On the other hand, ministerial work seems to be affected by higher levels of fluctuation than jobs in the regional offices. Second, we compare work tasks of MOs and ROs. As expected, MOs are more involved in analytical tasks and research than ROs. In contrast, ROs are more likely to implement policies or programs, direct and monitor programs or lower-level bodies, provide advice for political bodies of the region, negotiate with elected politicians, communicate with citizens and provide methodological guidance, train or lecture. Contrary to our theoretical expectations, we found a strong positive correlation between analytical and brokering tasks (communication and negotiation). We thus reject the hypothesis that analytical tasks are at odds with negotiating and communication. Instead,
\end{abstract}

1 This work was supported by a by the Programme for the Development of Fields of Study at Faculty of Social Sciences, Charles University, Prague (PRVOUK, No. 17) and Czech Science Foundation Grant entitled "Policy Workers in the Czech Public Administration: Practices, Professional Values and Identity" (no. P404/12/0725). Among other things, it relies on a large-N survey of ministerial officials. The survey would not have been possible without Dr. Libor Konvicka of STEM/MARK, who, unfortunately, passed away before its completion. With utmost gratitude, we dedicate this paper to the memory of Mr. Konvicka.

2 Associate Professor, Institute of Sociological Studies, Faculty of Social Sciences, Charles University in Prague, Prague, Czech Republic. 
it is concluded that most officials are multitaskers, and it is especially so in regional offices. It is hypothesized that this might be caused by the fact that regional offices are smaller and have a lower capacity to specialize.

Key words: Ministries; regional offices; policy analysis; policy work; sample survey; Czech Republic

\section{Introduction}

Ministries are somewhat enigmatic institutions for many people. Ministerial officials are usually guarded from ordinary citizens by reception clerks who reject all unauthorized visitors. Information on what concrete tasks are undertaken in a given ministry and which members of staff are responsible for them are often restricted. The same is true, though to a lesser degree, for sub-national government offices. Even for public-administration researchers it is usually not easy to be allowed to study internal ministerial processes and work that is actually being done there. It seems to be especially so in an administrative environment with a low level of trust, which is one of the significant features of public administration in CEE (Randma-Liiv 2008; Bouckaert et al. 2011; Veselý 2013a).

Surveys of public officials have, of course, for a long time been a well-established part of public-administration research (Lee et al. 2012). Until recently, however, the survey research focused upon topics such as public-service motivation, attitudes, beliefs etc., and surprisingly little attention was paid to the actual work that public officials do as well as their work profile. This started to change during the mid-2000s with qualitative case studies in the United Kingdom and the Netherlands (Page and Jenkins 2005; Colebatch 2006). At the same time, theories on so-called "policy work" in public administration has started to be formulated (Colebatch and Radin 2006; Colebatch et al. 2010; see also Kohoutek et al. 2013 for review). A bit later, a series of large-scale quantitative studies of Canadian federal and provincial policy bureaucrats were undertaken (e.g. Wellstead, Stedman and Lindquist 2009; Wellstead and Stedman 2010; Howlett and Newman 2010; Howlett and Wellstead 2012; Howlett and Walker 2012). Together with national surveys on public-administration officials in countries such as Norway or the Netherlands (e.g. 't Hart et al. 2007), we now have a solid base of empirical evidence from several of the most developed countries.

However, evidence from CEE countries is still very much limited, and just a few large-scale empirical surveys have been conducted in the region. The exception to this include a web-based survey of civil servants in the ministerial bureaucracies developed and managed by OECD in co-operation with RAND Europe (MeyerSahling 2009) and an executive survey on public-sector reform in Europe under the project "Coordinating for Cohesion in the Public Sector of the Future" (COCOPS), which was realized in Hungary, Lithuania, Serbia and Croatia. In other countries, 
such as the Czech Republic and Slovakia, there have also been several narrower and more specialized studies (Drulák et al. 2003; Scherpereel 2004). ${ }^{3}$

Even these exceptions, however, provide very little information on what people in public administration actually do and what their basic characteristics are. The aim of this paper is to fill this gap in knowledge by presenting hitherto unpublished data from two large-N empirical surveys that were recently carried out in the Czech Republic. The first objective of this article is to describe the main characteristics of ministerial officials (hereinafter "MOs") and compare them with the main characteristics of regional-level officials (hereinafter "ROs") on the basis of several theory-led hypotheses. The second objective is to analyze the main types of tasks MOs and ROs undertake and to reflect this evidence in light of existing theories about the nature of works in central and regional government administration. The two surveys were carried out within a one-year period, were based upon the same theoretical framework and shared identical questions. We thus not only can for the first time describe in depth the profile and work of public officials in one of the CEE countries, but also - and this can be of interest to scholars outside CEE - differences between two levels of government - central and regional.

\section{Theoretical background, hypotheses and research questions}

In this paper, we deal with two interrelated topics: 1) comparison of the profiles of ministerial and regional officials; 2) types of tasks and activities undertaken by ministerial and regional officials. We will first examine research questions, assumptions and the theoretical background of the first topic.

Regarding the profiles of MOs and ROs, we are particularly interested in the following questions: What kind of people work in these key offices? What kind of environments are they recruited from? How long have they been working in the office and how long are they planning to stay? Existing theory provides us with few answers to these profile questions. However, based on similar surveys abroad (especially in Canada) and practical experience with the situation of public administration in the Czech Republic, we can formulate a limited number of assumptions about the typical characteristics of MOs and ROs, as well as possible differences between them. First, international evidence (Howlett and Newman 2010) suggests that male officials are in the majority in central administration (ministerial officials) and female officials in regional administration. ${ }^{4}$ Second, MOs can be expected to be older than ROs, primarily because the regional offices are historically much younger institutions than ministries. When the regional offices were initially established in 2000, they probably recruited a considerable part of their staff from the abol-

3 For a comparison of ROs in Canada and the Czech Republic see Veselý et al. (2014, in press).

4 Admittedly, it remains unclear how this can be explained theoretically. 
ished system of district offices, but at the same time, they hired many candidates, including young people, from outside the public sector. This is related to another hypothesis, namely that ROs have, on average, shorter career histories in public administration than MOs.

Third, we can expect somewhat higher education levels among MOs, especially since education levels in Prague (where all the ministries are located) are generally higher than in the regions. Another reason is that ministries might have higher concentrations of jobs in analytical departments and units that require a rich educational background or even a scientific qualification. On a similar note, we expect differences in the composition of previous job experience. If government ministries are indeed responsible for more analytically demanding tasks, then they should be staffed by more people with experience from academia (universities, the Academy of Sciences etc.). In contrast, ROs should typically have their previous job experience from other bodies of public administration (such as the district offices).

The last profile question concerns the officials' career plans, and specifically their intention to stay with the present bureau. In this respect, it should be noted that Act No. 218/2002 Coll. (the so-called Civil Service Act) was still ineffective at the time of our data collection, while Act No. 312/2002 Coll. (on Civil Servants in Regional Government) was fully implemented. For that reason, civil servants in the entire central government administration were working under more precarious conditions than those employed at the regional level. Therefore, we expect MOs to have shorter career plans than ROs. This is further supported by the fact that employment opportunities in Prague are much better than in the regions. Consequently, MOs might be tempted to leave the ministerial job.

The second group of research questions relates to the actual work done by MOs and ROs. What kind of tasks do they undertake and how often? In what aspects of work do they differ from one another? The work of government ministries goes far beyond the "mere" drafting of regulations and the administration of diverse forms. As bodies of central government, ministries have extensive and highly heterogeneous responsibilities and powers. In the Czech Republic, the scope of their official authority is defined by Act No. 2/1969 Coll. (the so-called Competence Act). While the text of the law is relatively brief and abstract, it does prescribe a highly diverse array of responsibilities for the different ministries. They are obliged to coordinate individual bodies of public administration, prepare conceptual and strategic documents for their policy domains, prepare and table draft laws, provide information and methodological guidance, negotiate agreements, direct government inspection in specific areas, etc. The thirteen Czech regions (kraje) are autonomously governed and were only established in 2001 as a result of extensive decentralization (Baun and Marek 2006). Their administration is concentrated in regional offices. In contrast to ministries, which usually have a long history, Czech regions are thus rather new institutions. However, they also have a wide range of competencies and 
responsibilities, especially in social and health services, education, infrastructure development, environment protection etc. Officials at both central and regional government administration can also be expected to undertake a vast array of tasks.

Indeed, empirical evidence from other countries suggests that government and regional officials are no longer (if they ever were) just bureaucrats stamping and circulating documents. In fact, they "have numerous tasks including formal analysis, writing reports, managing the demands of the governmental process and above all, interacting with other players involved in the issue" (Colebatch et al. 2010, 15). The work of officials both at the central and regional levels include drafting legislation, writing policy papers, implementing various programs and projects, monitoring the work of lower-level bodies, formulating official positions on various issues etc. This is an immensely heterogeneous mix of tasks (Radin 2013).

In this paper, we are primarily interested in two categories of tasks which have thus far enjoyed the most theoretical and empirical attention. The first category concerns policy analysis (Dunn 2004). While English-speaking countries have a tradition of policy analysis, it has been institutionalized only recently in CEE. Policy analysis as a practically oriented discipline strives to provide clients (typically public officials with a decision-making authority) with such information and evidence that they can use in designing specific policies. Policy analysis typically includes problem definition, identification of alternative solutions, evaluation of such options and recommendations on what (not) to do. Traditional policy analysis is based on the assumption that what politicians (or other authorized officials) need for making a decision is a piece of frank and faithful advice derived from systematic analysis and based on the best available evidence. The main idea of traditional analysis can be expressed by the motto, "speaking truth to power", in which truth stands for maximum objectiveness. In the Czech context, as in any other CEE country, policy analysis is barely established as a discipline, and the term is rarely applied in practice. Nevertheless, we assume that the actual work of MOs and ROs in the Czech Republic also covers those tasks that are normally undertaken by policy analysts (gathering data and relevant information, defining problems, identifying alternative solutions, selecting options and formulating recommendations).

The other type of tasks on which we focus in this paper concerns communication and negotiation with other actors. As many authors have noted, merely "speaking truth" often does not result in better policy choices. ${ }^{5}$ The policy process is typically not so much about "finding the truth" but rather about finding a consensus, or reconciling different interests, values and beliefs. In the words of Robert Hoppe (1999), "speaking truth to power" is less important than "making sense together" - striving to identify shared meanings and mutual recognition. In this

5 Traditional policy analysis has been criticized also from epistemological perspectives. However, for the purpose of the present discussion, we take the liberty of leaving the questions about the nature of "objective knowledge" aside. 
respect, many authors argue that it is increasingly important to communicate with other actors in public administration and beyond, while tasks such as data analysis or cost-and-benefit evaluation of policy options are receiving less attention (Colebatch and Radin 2006).

In other words, it can be argued that the amount of work in the domain of traditional policy analysis (data collection and analysis, assessment of options) is negatively correlated to the intensity of communication and negotiation. The fewer analytical tasks a given institution undertakes, the more it communicates with other actors, and vice versa. In the absence of relevant longitudinal data, we can attempt to test this idea by comparing the tasks undertaken in different types of institutions or geographical locations. Interestingly in this respect, Rasmussen et al. (unpublished) compared the work of regional bureaucracies in the small Canadian province of Saskatchewan with two of Canada's largest provinces. In small jurisdictions like Saskatchewan, few institutions specialize on policy analysis. Based on their findings, the authors have concluded that public officials in such small jurisdictions obtain the necessary information through more active involvement in various networks.

Several theoretical arguments have been formulated to support the hypothesis that analytical tasks are at odds with brokering and networking. The first possible reason for this lies in the assumed decline of public administration's expert capacities due to outsourcing. Policy analytical capacities were traditionally concentrated within the confines of public administration, but in the course of the 1990s, the ideology of New Public Management influenced many developed countries to change their methods of producing the underlying analysis for policy decisions. Public administration has been under considerable political pressure to cut down on internal expertise and outsource a growing portion of its analytical tasks (Craft and Howlett 2013; Veselý 2012, 2013b). It can be argued that as public-administration bodies produced less analysis on their own, they had to reorient themselves on the process of public procurement and communication with bidders. That is, instead of production of internal analysis, officials are assumed to be more involved in communication with those outside the administration who actually produce it.

Another line of argument supporting the division between analysis and communication concerns general changes in governance. The political systems of developed countries have been undergoing profound changes in many respects. A lot of decision-making has been transferred from the central level to the regional and local levels, a trend referred to as "multilevel governance" (Hooghe and Marks 2003). Policy processes have been colonized by a multitude of new actors (Colebatch 2006) and increasingly shaped by networks of actors, rather than traditional hierarchies (Rhodes 1996). Many authors have argued that in a "network society" central governments are increasingly unable to assert their policies through "hierarchical relations". With the broadening array of actors involved in the policy process, it is no longer possible for any single organization (including central government and its 
ministries) to pursue its mission on its own, separately from others (Koppenjan and Klijn 2004). Over the past two decades, public administration underwent considerable decentralization, with decision-making powers transferred to lower levels of government. This was accompanied by a growing role of supra-national institutions, especially the European Union. With the fragmentation of policy-analytical capacities grew the need to create links and share information between the different levels of governance.

How are these theoretical assumptions reflected in the everyday work of public officials? What is the proportion of "analysts" and "brokers" in public administration? Are policy-analysis tasks really at odds with negotiation and networking? According to the above theories, we should assume the existence of a large group of officials whose job it is solely to communicate and negotiate with citizens and other institutions of the public, civic and private sectors. Since working hours are always limited and attention can only be split between a finite number of priorities, one would hypothesize a negative correlation between these two types of work, with individual officials typically involved either in analysis or in brokering. In the absence of longitudinal data, we cannot verify changes in the proportion of analytical and brokering tasks over time. However, by comparing the officials working in central and regional administration, we can test the hypothesized relationship between organizational size and the extent of analytical tasks, assuming that ROs are involved less in analysis but more in communication/brokering, while MOs do more analysis and less communication/brokering.

Counterarguments against the hypothesis that there is a negative correlation between analytical and brokering tasks might be, however, also formulated. Both types of work require the same set of skills and need not be mutually exclusive. Thus, the tasks of policy analysis and brokering may be conflicting in some cases (negative correlation) and complementary in other cases (positive correlation). This may vary from organization to organization, depending on its size and age. Smaller and historically younger bodies of regional government can be expected to exhibit a more complementary relationship between the two types of work. Conversely, in the context of the larger and older ministries with more heterogeneous responsibilities, officials should have more opportunities and find it more essential to specialize and choose between the different types of work. In other words, we expect a closer coexistence between policy analysis and brokering tasks in the work of ROs.

\section{Methodology and data}

In this paper we use data from two recently realized large-N empirical surveys. One survey targeted ROs and the other one MOs. The target group was defined as all employees of a given ministry or regional office except those involved exclusively in its internal operations (car fleet, maintenance, secretariat, accounting etc.). In 
both surveys, research design and the questionnaire were strongly inspired by the recent Canadian studies. Our questionnaire was based on the original research instrument of Adam Wellstead, Michael Howlett and their colleagues. The MO and $\mathrm{RO}$ questionnaires were basically identical, with a few new questions added for the MO survey.

As for the RO survey, data collection by means of CAWI (Computer-Aided Web Interviews) took place between September and November 2012. Prior to that, we compiled contact information from the official websites of the different Regional Offices and created a complete list of the ROs targeted (sample frame, 2615 contacts). All ROs in the sample frame were sent an email invitation to participate in the survey, which consisted of a link to the online instrument and a motivation letter from the organizers. 200 email contacts bounced and were identified as invalid. A total of 783 questionnaires were completed in full, resulting in a total response rate of $32.4 \%$.

Data collection in the MO survey was organized between April and July 2013. Staff directories with contact information were found online for only 2 out of 14 ministries; the rest of them treated such directories as confidential. Step by step, 11 ministries agreed to participate in the survey (and disclose their staff directories, which served us as our sample frame). In seven ministries, data was collected by face-to-face interviewing: interviewers met with respondents, asked them a series of predefined standard questions and recorded their answers on a paper form (CAPI) or in a computer application (PAPI). For two ministries which preferred to participate without the involvement of interviewers, data was collected by the administration of online questionnaires (CAWI). In one ministry, a combination of CAPI and CAWI was implemented. The respondents were selected randomly from each ministerial sample frame. However, after a number of waves of random sampling, all individuals from each sample frame were eventually invited to participate. Thus, what was intended to be random sampling turned out as a census. A total of 1351 complete questionnaires were obtained, and the response rate was $29.4 \%$.

Both surveys were faced with methodological challenges. Especially the MO survey underwent several refinements to its research design due to the different ministries' specific demands (e.g. CAWI) or limitations (e.g. job positions not identified in staff directory). For these reasons, we made an extraordinary effort to keep our methodology as rigorous and transparent as possible. Detailed methodological information about this survey can be found in a special article (Veselý 2013a), which also discusses in more detail the methodological challenges of implementation and of the possible limitations of the data obtained. The relatively low response rate (compared to "classical" opinion surveys) has been identified as the central issue. Nevertheless, response-rate issues are normal for this type of studies, and our response rate was equal to or higher than that the levels reached in similar surveys 
among government officials abroad. ${ }^{6}$ The analysis did not reveal any systematic bias, and we did not identify any reasons to believe that the data should be affected by it. Although the results of the analysis should be interpreted with caution (especially with regard to smaller units), the sample size and the sampling procedure guarantee both unique and sufficiently robust data to allow unprecedented insight in the everyday realities of work in Czech government administration at the central and regional levels. ${ }^{7}$

\section{Empirical analysis}

\subsection{Profile of ministerial and regional officials}

Our data enables a comparison between MOs and ROs on a series of parameters. Selected basic characteristics of both groups are shown in Table 1. Although most of the differences are statistically significant, they vary in magnitude from variable to variable. What stands out at first sight (and more or less meets our expectations) is the difference in gender ratio: equal numbers of men and women work in Czech ministries, while the majority of ROs are women (61.7\%).

As for age, MOs are on average two years older than ROs, which is in accordance with our hypothesis. While officials around thirty represent the strongest age group at both levels of government, there are differences in other aspects of the age structure. The age distribution of the ROs is more even, with fewer demographic "indentations". Additional differences become apparent when three age groups are defined (younger than 35, 35-49 and 50+). The youngest group is represented equally in both levels of (32\% of MOs and $33 \%$ of ROs are younger than 35 ), and the middle-age group accounts for $32 \%$ of MOs and $39 \%$ of ROs. The main difference is in the oldest category: persons aged $50+$ comprise only $28 \%$ of ROs but as many as $37 \%$ of MOs. In other words, the age structure of ministerial staff is weaker in the middle generation, while middle-aged officials form the "spine" of regional administration. In ministries, there is a large group of officials in pre-retirement or retirement age.

The data on education is also in line with our expectations: the overall education level of MOs is somewhat higher than that of ROs. Both groups are generally well-educated, with more than $90 \%$ of MOs and more than $88 \%$ of ROs having at least a Bachelor's degree. The Master's degree is clearly predominant ( $71 \%$ of MOs,

6 The response rate in the survey of MOs in seven new member states of the EU, which was implemented by RAND and OECD, ranged typically between $20 \%$ and $25 \%$; Slovakia was the only country to exceed $25 \%$, while Hungary reached as little as $10 \%$ (Meyer-Sahling 2009, 89).

7 It should also be noted that in this paper we analyze the whole sample and do not discriminate between levels of officials (e.g. senior, mid-level, lower level). We are aware that the position in public-administration hierarchy can have a significant impact on profile and tasks (e.g. Kabele and Hájek 2008; Howlett 2011). Thus it will be useful in the future to run separate analyses for different levels of public officials. 
$70 \%$ of ROs). Persons with a Bachelor's degree account for $12 \%$ of ROs, compared to $7 \%$ of MOs; conversely, there are more workers with doctorates in the ministries $(13 \%)$ than in the regions (6\%). Both these numbers are quite high, given the total number of PhDs in the Czech workforce. Undoubtedly, the generally high levels of education among MOs and ROs are caused by the fact that a university degree is a typical job requirement; it remains difficult to interpret the high proportion of officials with a PhD degree.

The survey also included a question about the number of years spent in civil service. As the MOs are generally older, it is not surprising that they also have worked as civil servants for more years. Nevertheless, MOs and ROs have the same mean number of years spent in the present ministry or regional office. Further analysis revealed a higher variance of this parameter among MOs, with bigger groups of those who have been in the ministry for less than 6 years (50\%, compared to $45 \%$ of ROs) or more than 10 years ( $31 \%$, compared to $23 \%$ of ROs). This suggests the existence of at least two typical categories of ministerial workers in terms of their history in the present institution: "veterans" and a large group of relative "freshmen". The middle group of officials who have worked in the ministry for 6-10 years is relatively small, compared to the regional level.

The above findings allow us to draw one tentative conclusion: with the exception of "veterans", the jobs of ministerial officials are more precarious, i.e. affected by higher levels of fluctuation, than jobs in the regional offices. This interpretation is further supported by data about individual plans to stay with the present employer. On average, MOs are planning to stay fewer years, with as many as $7 \%$ planning to leave in less than a year (compared to just $2 \%$ of ROs), and only $22 \%$ of MOs maintain a long-term perspective of more than 10 years (compared to $39 \%$ of ROs). Further analysis by age groups reveals that this discrepancy is not primarily caused by the higher mean age of MOs. In contrast, the absence of a job perspective with the present employer affects young MOs (under 30) more than young ROs. This may be caused by several reasons. First, due to the absence of the effective Civil Service Act or other obstacles, young people may find little perspective in their ministerial jobs. Also, because all ministries are located in Prague with its rather abundant job opportunities, a large group of young MOs may consider public service merely as a start-up job bridging the time between university and a more desirable stage of their professional career. In contrast, since there are fewer opportunities for highly qualified workers while in the regional capitals, a regional office job may represent one of the few stable career perspectives for people with a university degree (or even a $\mathrm{PhD}$ ).

Another question concerned the officials' prior career histories. As hypothesized, MOs are somewhat more likely than ROs to have an academic job on their resume. Not surprisingly, MOs are more likely to have prior job experience from central government administration and ROs from district offices or other bodies 
of regional administration. The two levels of government have equal percentages of officials without prior job experience (who came straight from university) or with experience from the NGO sector. Surprisingly, relatively many MOs have job experience from the business sector ( $43 \%$, compared to $25 \%$ of ROs). This finding is difficult to interpret and contradicts the common stereotype of "career bureaucrats" who join the ranks of civil service immediately after university and remain completely untouched by business experience. In the future, it would surely be interesting to examine MOs' motivations for this kind of career change (perhaps higher pay, higher job security, shorter hours, higher self-efficacy in terms of public interest etc.).

\subsection{Tasks undertaken}

The other group of research questions concerns the tasks MOs and ROs actually undertake in their jobs. Two items of the questionnaires are relevant for this purpose. First, the respondents were presented with a list of tasks and asked whether or not they were personally involved in each of them (Table 2a). This was a dichotomous (yes/no), multiple-choice question (respondents were free to tick as many options as they wanted). Inspired by the Canadian surveys, the second item consisted of a battery measuring the frequency of involvement in each type of tasks (Table $2 b$ ). The wording of questions was identical for MOs and ROs, with only a few minor exceptions. ${ }^{8}$ Apart from these exceptions, all items are directly and fully comparable.

As Tables $2 \mathrm{a}$ and $2 \mathrm{~b}$ show, only few tasks are undertaken to the same extent by both MOs and ROs (these include budgeting and communication with other bodies of the public sector or with NGOs, and partly also the preparation of conceptual/strategic policy documents). All other types of tasks display clear differences between the two groups of officials. MOs are more likely to undertake data collection, research, problem identification and identification of possible solutions. Thus, as expected, MOs are more involved in analytical tasks and research than ROs. However, in absolute terms, MOs do not display high levels of "research capacities". As many as $65 \%$ of MOs (and the same percentage of ROs) stated they were never involved in research tasks, while only $5 \%$ of MOs dealt with them daily or several times a week. Somewhat surprisingly, ROs also display a higher prevalence of routine administrative acts.

In contrast, ROs are more likely to implement policies or programs, direct and monitor programs or lower-level bodies, provide advice for political bodies of the

8 The question on "preparing conceptual and strategic policy documents of ..." referred to "the Ministry" for MOs and "the Region" for ROs. The question referring to "organizations directly controlled" by the ministry was administered to MOs only. Finally, the question about consultations/negotiations with politicians was administered to MOs as two separate questions, one referring to politicians working in the same office (e.g. the Minister or Deputy Ministers) and the other one to those working elsewhere; this distinction was irrelevant to regional offices because they are headed by career bureaucrats, not elected politicians. 


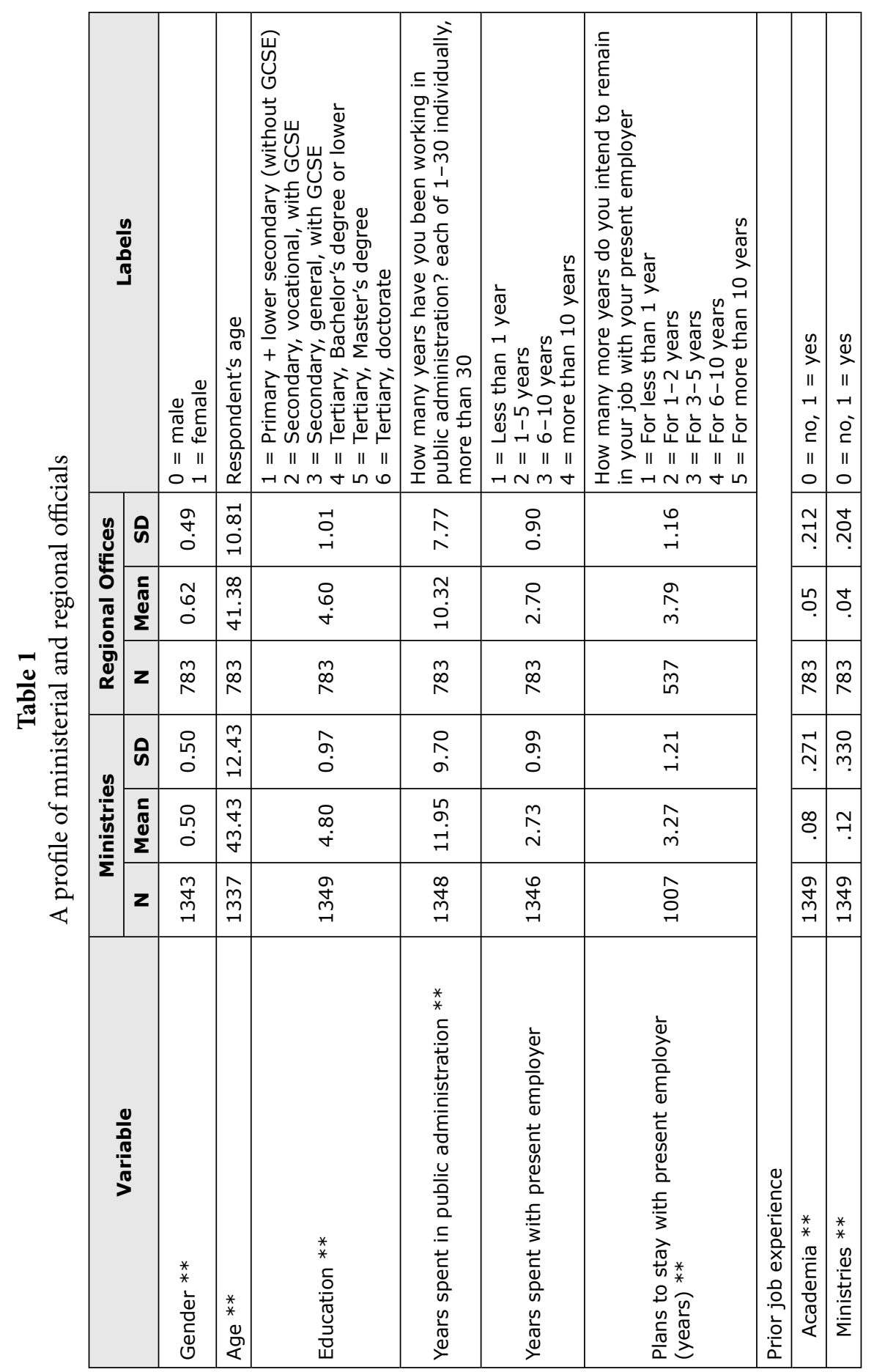




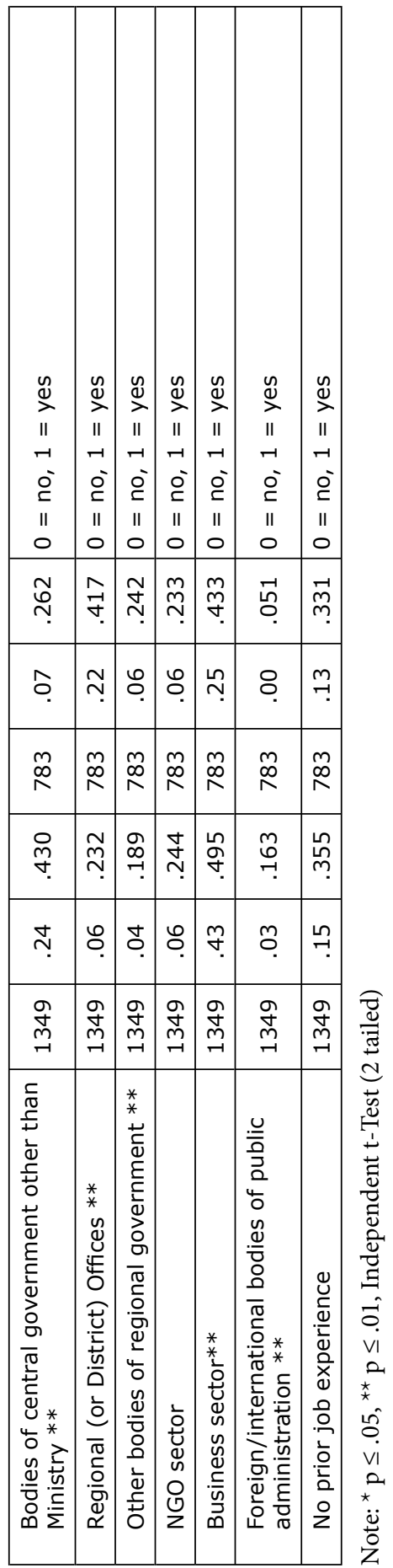




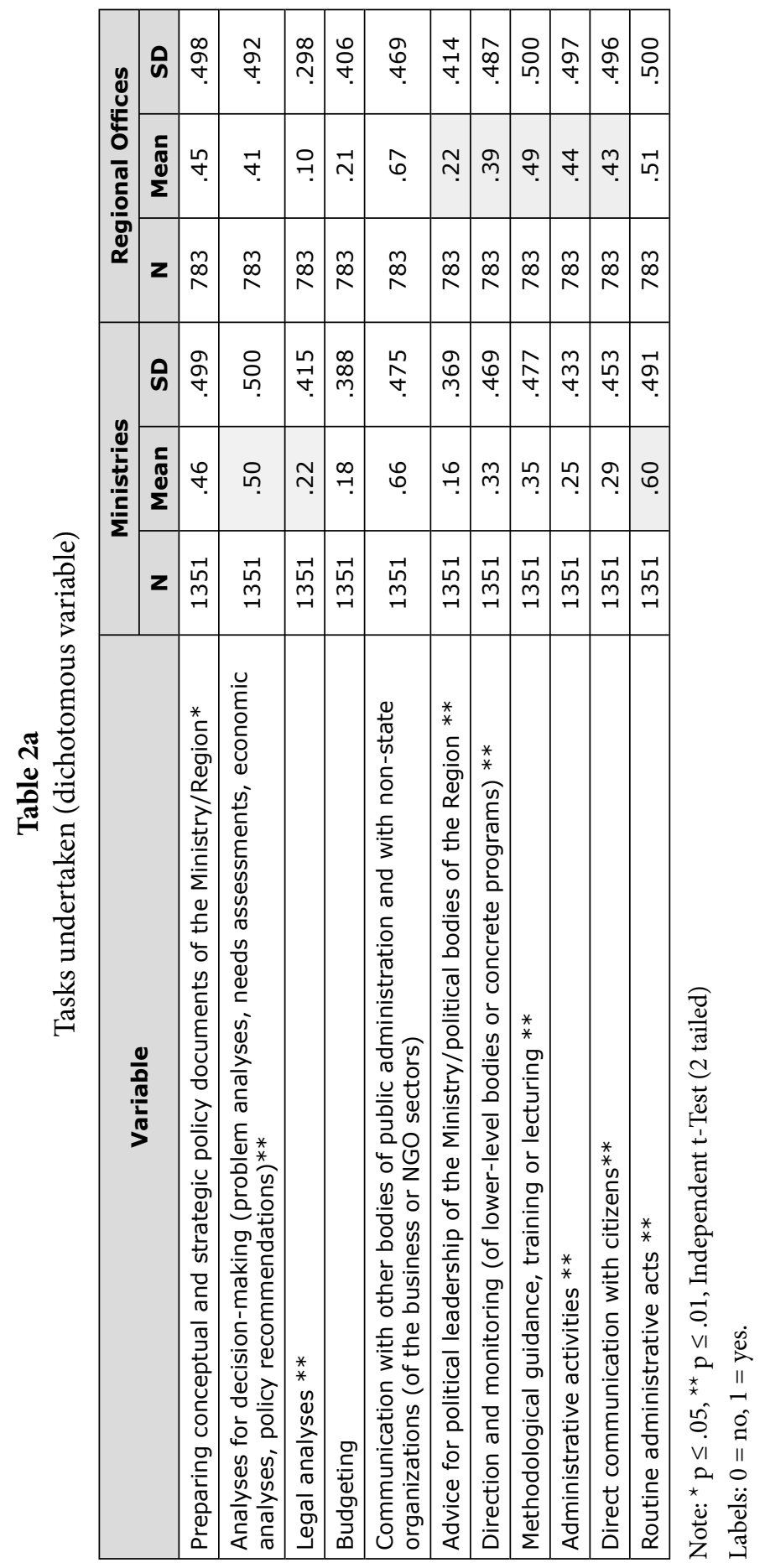




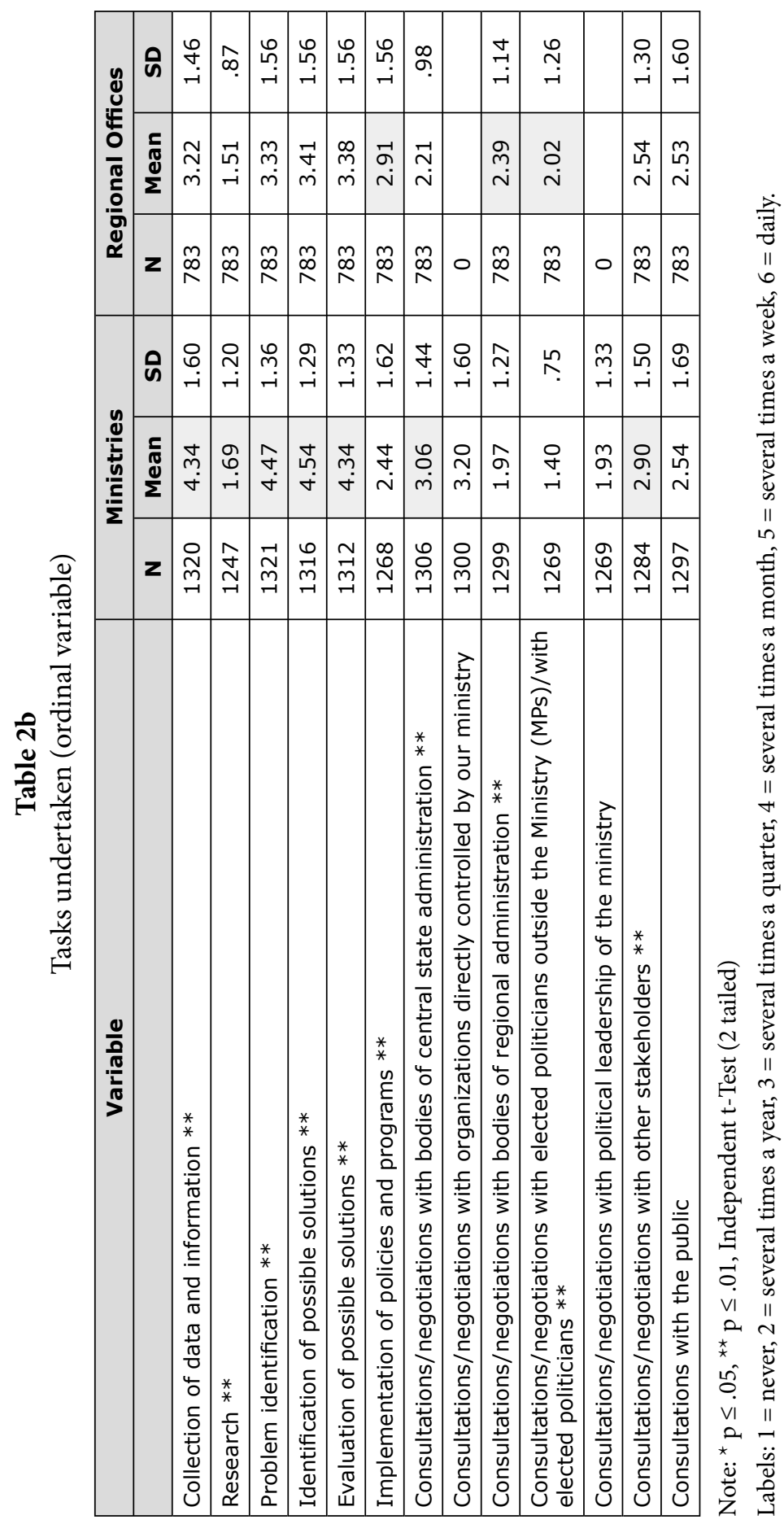


region, negotiate with elected politicians, communicate with citizens and, perhaps somewhat surprisingly, provide methodological guidance, train or lecture. Equally surprising is the lower average intensity of routine administrative acts among ROs.

\subsection{Analysts or brokers?}

The last research concerned the extent to which policy-analytical tasks are complementary to or mutually exclusive with tasks such as negotiation or communication. In order to test that hypothesis, we have reduced the tasks undertaken by MOs and ROs to two internally consistent composite variables. Based upon results of factor analysis and the theoretical background explained above, we have created two composite variables. The first variable, labelled "analytical tasks" includes: collection of data and information, problem identification, identification of possible solutions and evaluation of possible solutions. The second variable, referred to as "brokering tasks", includes: consultations or negotiations with bodies of central state administration, with bodies of regional administration, with elected politicians or with other stakeholders and consultations with the public. The value of each composite variable was defined as the sum of the frequencies of the different tasks included where 1 equals never and 6 equals daily. While the level of internal consistency is satisfactory for both composite variables, it is higher for analytical tasks than for brokering tasks.

\section{Table 3}

Composite variables - analytical tasks/brokering tasks

\begin{tabular}{|c|c|c|}
\hline \multirow{5}{*}{ 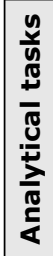 } & Collection of data and information & \\
\hline & Problem identification & \\
\hline & Identification of possible solutions & \\
\hline & Evaluation of possible solutions & \\
\hline & Cronbach's a & 0.90 \\
\hline \multirow{6}{*}{ 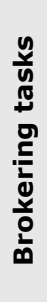 } & Consultations/negotiations with bodies of central state administration $* *$ & \\
\hline & Consultations/negotiations with bodies of regional administration $* *$ & \\
\hline & Consultations/negotiations with elected politicians outside the Ministry (MPs) & \\
\hline & Consultations/negotiations with other stakeholders $* *$ & \\
\hline & Consultations with the public & \\
\hline & Cronbach's a & 0.63 \\
\hline
\end{tabular}

Table 4 below gives more information on the intensity of analytical and brokering tasks in the two samples generally, and for each ministry specifically. It is immediately apparent that both MOs and ROs tend to undertake analytical tasks much more frequently than brokering tasks. As expected, MOs are more likely 
to undertake analytical tasks. As the intensity of brokering tasks is approximately the same in both samples, we have rejected the hypothesis that organizations with lower involvement in analytical tasks are more preoccupied with communication and negotiation. As for the distribution of analytical and brokering tasks between ministries, the highest intensity of analytical tasks is exhibited by the Ministries of Foreign Affairs, Defense and Transportation, and the lowest levels by Labor and Social Affairs, Justice, and Education, Youth and Sports. It should be noted that these results do not suggest that some ministries are "better" than others because they tell us nothing about the complexity and quality of their policy-analytical efforts. However, possible structural differences between the ministries cannot be ruled out, and it would certainly be interesting to examine more thoroughly why MOs in "social" ministries (that are responsible for public services such as health care, education or social welfare) exhibit the lowest intensity of analytical tasks and, at the same time, slightly above-average involvement in brokering tasks.

Table 4

Analytical and brokering tasks by institution

\begin{tabular}{|l|c|c|c|c|c|c|}
\hline \multirow{2}{*}{} & \multicolumn{3}{|c|}{ Analytical tasks } & \multicolumn{3}{c|}{ Brokering tasks } \\
\cline { 2 - 7 } & $\mathbf{N}$ & Mean & SD & N & Mean & SD \\
\hline Foreign Affairs & 58 & 4.78 & 1.00 & 53 & 2.56 & 0.83 \\
\hline Defense & 219 & 4.64 & 1.08 & 218 & 1.96 & 0.72 \\
\hline Transportation & 102 & 4.51 & 1.13 & 101 & 2.59 & 0.91 \\
\hline Finance & 122 & 4.42 & 1.07 & 123 & 2.27 & 0.77 \\
\hline Environment & 78 & 4.41 & 1.16 & 68 & 2.31 & 0.77 \\
\hline Culture & 140 & 4.37 & 1.25 & 141 & 2.44 & 0.94 \\
\hline Industry and Trade & 79 & 4.37 & 1.14 & 64 & 2.40 & 0.79 \\
\hline Health & 124 & 4.36 & 1.24 & 126 & 2.51 & 0.89 \\
\hline Education, Youth and Sports & 80 & 4.33 & 1.12 & 80 & 2.51 & 0.88 \\
\hline Justice & 103 & 4.29 & 1.23 & 103 & 2.33 & 0.80 \\
\hline Labor and Social Affairs & 174 & 4.26 & 1.11 & 175 & 2.43 & 0.74 \\
\hline Ministries total & $\mathbf{1 2 7 9}$ & $\mathbf{4 . 4 3}$ & $\mathbf{1 . 1 5}$ & $\mathbf{1 2 5 2}$ & $\mathbf{2 . 3 5}$ & $\mathbf{0 . 8 4}$ \\
\hline Regional Offices total & $\mathbf{7 8 3}$ & $\mathbf{3 . 3 3}$ & $\mathbf{1 . 4 0}$ & $\mathbf{7 8 3}$ & $\mathbf{2 . 3 3}$ & $\mathbf{0 . 6 0}$ \\
\hline
\end{tabular}

Table 5 indicates individual-level correlations between analytical tasks and brokering tasks. There is clearly a strong positive association between these two types of tasks: officials involved in analytical tasks are also more likely to undertake brokering tasks. It is in sharp contrast with the hypothesis that analytical and brokering activities are at odds. Quite the opposite is the case - these types of tasks are highly complementary both among MOs and even more so among ROs. A comparison between ministries reveals high differences in the strength of the relation- 
ship between analytical and brokering tasks, with the highest levels of correlation measured for the Ministries of Foreign Affairs, Transportation, Environment, and Industry and Trade. This suggests that "social" ministries might exhibit higher levels of specialization between analytical and brokering tasks than the other ministries. It also indicates the often overlooked fact that the nature of policy work differs between policy domains, e.g. between the so-called "power" and "social" ministries.

\section{Table 5}

Correlation between analytical and brokering tasks

\begin{tabular}{|l|c|c|c|}
\hline & Pearson's r & N & Sig. \\
\hline Foreign Affairs & $.447^{* *}$ & 53 & .001 \\
\hline Transportation & $.415^{* *}$ & 100 & .000 \\
\hline Environment & $.388^{* *}$ & 66 & .001 \\
\hline Industry and Trade & $.360^{* *}$ & 63 & .004 \\
\hline Defense & $.328^{* *}$ & 215 & .000 \\
\hline Culture & $.321^{* *}$ & 140 & .000 \\
\hline Justice & $.302^{* *}$ & 103 & .002 \\
\hline Labor and Social Affairs & $.264^{* *}$ & 173 & .000 \\
\hline Education, Youth and Sports & .182 & 79 & .109 \\
\hline Finance & .175 & 122 & .055 \\
\hline Health & .085 & 124 & .346 \\
\hline Ministries & $\mathbf{0 . 2 5 7 * *}$ & $\mathbf{1 2 3 7}$ & $\mathbf{. 0 0 0}$ \\
\hline Regional Offices & $\mathbf{0 . 5 2 9 * *}$ & $\mathbf{7 8 3}$ & $\mathbf{. 0 0 0}$ \\
\hline Combined dataset & $\mathbf{0 . 3 5 2 * *}$ & $\mathbf{2 0 2 0}$ & $\mathbf{. 0 0 0}$ \\
\hline
\end{tabular}

Note: ${ }^{*} \mathrm{p} \leq .05,{ }^{* *} \mathrm{p} \leq .01$

\section{Discussion and conclusions}

Scholarly articles are often concluded with a call that "more research is needed", and we could certainly make use of that cliché as well. In this paper, we have opened a topic which is marked by large gaps in empirical evidence. We have been able to fill some of these gaps with results from two original surveys. Some of our findings confirm our hypotheses based upon theoretical background and findings from other jurisdictions. However, at the same time, other findings lead to new questions and challenge current theoretical assumptions. At the moment, for instance, we are not able to fully explain the high level of MOs' previous experience in the business sector or why ROs display such a high level of providing methodological guidance, training or lecturing. Other findings, such as the assumed lower stability of work in 
ministries, can be reasonably explained by factors such as an ineffective Civil Service Code. This, too, however, should be confirmed by further research.

Our analysis of work tasks has been led by the hypothesis that in current public-administration negotiation, communication and networking become more and more prevalent, and that this can be at odds with analytical tasks. Our data strongly rejects this hypothesis. Most officials are multitaskers. It is not by accident that several respondents used the open question asking them to describe their work activities commenting that they felt like "Ferdy the Ant - work of all kinds". Ferdy the Ant is a hero from famous books by Czech writer Ondřej Sekora. Ferdy is an extraordinary ant with a lot of diverse experience and challenges, which he is able to solve with manifold abilities and skills. In the Czech discourse, Ferdy the Ant is a synonym for a person who has to - and is able to - do many quite diverse things.

The "Ferdy phenomenon", as we could call it, seem to be especially visible in regional offices. It might be caused by the fact that regional offices are on average smaller than ministries, and there is thus a lower capacity to specialize on particular tasks such as analysis. It is also true that in ministries with a higher number of employees (such as the Ministry of Education, Youth and Sports and the Ministry of Finance) the correlation between analytical and brokering tasks is lower than in smaller ministries such as the Ministry of Culture or the Ministry of Transportation). However, there is no clear linear trend. For instance, the Ministry of Health, where the correlation is the lowest, is a relatively small ministry.

In any event, analytical and brokering tasks seem to be rather complementary, although we are not sure why. We can hypothesize that the line between different groups of officials is drawn along the intensity of their work, rather than its content. The actual tasks undertaken by any given MO or RO may somewhat deviate from their official job description. Like any other institution, public administration is occupied both by people who live for their work, strive to be active and efficient and work extra hours when necessary ${ }^{9}$, and by others who work to earn their living and do not seek any special engagement. Based on our data, we would also assume that in order to do the job of policy analysis thoroughly, one needs to spend some extra time consulting and negotiating. In other words, those who honestly strive to identify problems and recommend solutions find it necessary to consult their opinions with those stakeholders who are most affected by these problems.

Finally, the findings of our analysis also feed back into the theoretical framework. The nature of the work in public administration seems to depend on a number of additional factors that tend to be overlooked. Besides macro-structural factors such as decentralization, multilevel governance and the growing role of networking, we have identified a number of mezzo- and micro-factors such as: size of the bureau, age of the institution, policy domain (health, social affairs etc.) or

9 It would be very interesting to examine this type of leaders in the ranks of ministerial and regional officials. 
employment opportunities in the region. There is also a specifically Czech factor, the precarious employment situation of MOs given by the ineffective Public Service Act. The fact that our data was collected in 2013, i.e. before the Act came into effect, gives us the opportunity to make a comparison in the future to see the difference such a regulatory framework would make.

\section{References}

Baun, Michael and Dan Marek. 2006. "Regional Policy and Decentralization in the Czech Republic." Regional \& Federal Studies 16(4), 409-428.

Bouckaert, Geert, Vitalis Nakrošis and Juraj Nemec. 2011. "Public Administration and Management Reforms in CEE: Main Trajectories and Results." NISPAcee Journal of Public Administration and Policy 4(1), 9-29.

Colebatch, Hal K. (ed.). 2006. The Work of Policy: An International Survey. Oxford: Lexington Books.

Colebatch, Hal K., Robert Hoppe and Mirko Noordegraaf (eds). 2010. Working for Policy. Amsterdam: Amsterdam University Press.

Colebatch, Hal K. and Beryl A. Radin. 2006. "Mapping the work of policy." In Hal K. Colebatch (ed.). The Work of Policy: An International Survey. Lanham: Lexington Books, pages, 217-226

Craft, Jonathan and Michael Howlett. 2013. "The Dual Dynamics of Policy Advisory Systems: The Impact of Externalization and Politicization on Policy Advice." Policy and Society 32(3), 187-197.

Drulák, Petr, Jiř́ Česal and Stanislav Hampl. 2003. "Interactions and Identities of Czech Civil Servants on their Way to the EU." Journal of European Public Policy 10(4), 637-654.

Dunn, William N. 2004. Public Policy Analysis: An Introduction. $3^{\text {rd }}$ edn. Upper Saddle River, NJ: Prentice Hall.

Hooghe, Liesbet and Gary Marks. 2003. "Unraveling the Central State, but How? Types of Multi-Level Governance." The American Political Science Review 97(2), 233-243.

Hoppe, Robert. 1999. "Policy Analysis, Science and Politics: From 'Speaking Truth to Power' to 'Making Sense together.' Science and Public Policy 26(3), 201-210.

Howlett, Michael. 2011. "Public Managers as the Missing Variable in Policy Studies: An Empirical Investigation Using Canadian Data." Review of Policy Research 28(3), 247-263. 
Howlett, Michael and Joshua Newman. 2010. "Policy Analysis and Policy Work in Federal Systems: Policy Advice and its Contribution to Evidence-Based Policy-Making in Multi-Level Governance Systems." Policy and Society 29(2), $123-136$

Howlett, Michael and Richard M. Walker. 2012. "Public Managers in the Policy Process: More Evidence on the Missing Variable?” Policy Studies Journal 40(2), 211-233.

Howlett, Michael and Adam M. Wellstead. 2012. "Professional Policy Work in Federal States: Institutional Autonomy and Canadian Policy Analysis." Canadian Public Administration 55(1), 53-68.

Kabele, Jiří and Martin Hájek. 2008. Jak vládli? Průvodce hierarchiemi reálného socialismu [How they governed? The guide through hierarchies of 'really existing socialism']. Brno: Doplněk.

Kohoutek, Jan, Martin Nekola and Vilém Novotný. 2013. "Conceptualizing Policy Work as Activity and Field of Research." Central European Journal of Public Policy 7(1), 28-59.

Koppenjan, Johannes Franciscus Maria and Erik-Hans Klijn. 2004. Managing Uncertainties in Networks: A Network Approach to Problem Solving and Decision Making. London: Routledge.

Lee, Geon, Jennifer Benoit-Bryan and Timothy P. Johnson. 2012. "Survey Research in Public Administration: Assessing Mainstream Journals with a Total Survey Error Framework." Public Administration Review 72(1), 87-97.

Meyer-Sahling, Jan-Hinrik. 2009. Sustainability of Civil Service Reforms in Central and Eastern Europe Five Years after EU Accession, Sigma Papers. Paris: OECD.

Page, Edward and Bill Jenkins. 2005. Policy Bureaucracy: Government with a Cast of Thousands. Oxford: Oxford University Press.

Radin, Beryl A. 2013. “Policy Analysis Reaches Midlife." Central European Journal of Public Policy 7(1), 8-27.

Randma-Liiv, Tiina. 2008. "New Public Management versus the Neo-Weberian State in Central and Eastern Europe." NISPAcee Journal of Public Administration and Policy 1(2), 49-71.

Rasmussen, Ken, Jim Marshall, Adam Wellstead and Bryan Evans. (Unpublished). "Policy Work in Subnational Jurisdictions: Does Size Determine Role?".

Rhodes, Roderick Arthur William. 1996. "The New Governance: Governing without Government.” Political Studies 44(4), 652-667.

Scherpereel, John A. 2004. "Renewing the Socialist Past or Moving toward the European Administrative Space? Inside Czech and Slovak Ministries." Administration \& Society 36(5), 553-593. 
't Hart, Paul, Karin Geuijen, Sebastiaan Princen, Kutsal Yesilkagit, and Ellen Mastenbroek. 2007. The Europeanization of the Civil Service Craft. Report presented to the Dutch Ministry of the Interior (BZK).

Veselý, Arnošt. 2013a. "Conducting Large-N Surveys on Policy Work in Bureaucracies: Some Methodological Challenges and Implications from the Czech Republic." Central European Journal of Public Policy 7(2), 88-113.

Veselý, Arnošt. 2013b. "Externalization of Policy Advice: Theory, Methodology and Evidence." Policy and Society 32(3), 199-209.

Veselý, Arnošt. 2012. "Policy Advisory System in the Czech Republic: From State Monopoly to Hollowing out?" Paper presented at $22^{\text {nd }}$ World Congress of Political Science. 8-12 July 2012, Madrid.

Veselý, Arnošt, Adam Wellstead and Bryan Evans. 2014 (in press). "Comparing Sub-National Policy Workers in Canada and the Czech Republic: Who Are they, what they Do, and why it Matters?" Policy and Society 2.

Wellstead, Adam, Stedman, Richard C., \& Lindquist, Evert (2009). The Nature of Regional Policy Work in Canada's Public Service. Canadian Political Science Review, 3(1), 34-56.

Wellstead, Adam, Stedman, Richard. 2010.. Policy Capacity and Incapacity in Canada’s Federal Government. Public Management Review, 12(6), 893-910. 